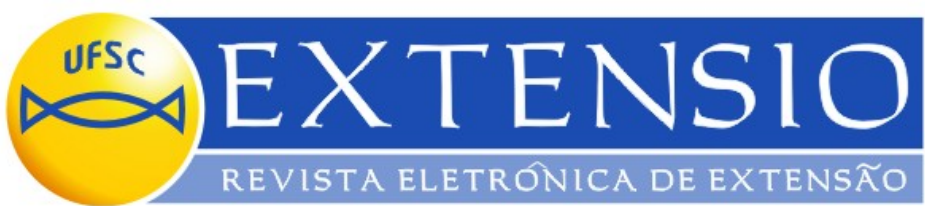

\title{
SAÚDE MENTAL E ECONOMIA SOLIDÁRIA: ESTRATÉGIAS DE REABILITAÇÃO PSISSOCIAL
}

\author{
Me. Edelu Kawahala \\ Mestre em Psicologia pela UFSC \\ Marcelo Lucas Paines \\ Bacharel em Psicologia pela UNESC \\ Rodrigo Diaz de Vivar y Soler \\ Aluno do Mestrado em Psicologia da UFSC \\ Dr. Sandro Kobol Fornazari \\ Doutor em Filosofia pela USP \\ Me. Marlon Xavier \\ Mestre em Psicologia Social pela PUC/RS (Coordenador) \\ marlonx73@gmail.com
}

\section{Resumo}

Este artigo tem por objetivo apresentar considerações acerca de um Projeto de Extensão desenvolvido no ano de 2006 em uma parceria entre o curso de Psicologia da UNESC e o Centro de Atenção Psicossocial ${ }^{1}$. Tendo como pressuposto a economia solidária, o projeto procurou, em conjunto com a comunidade, construir uma associação de usuários, oportunizando estratégias de geração de renda e reabilitação psicossocial. No prazo de um ano de atividade, tal associação foi constituída e hoje é gerenciada pelos usuários.

Palavras-chave: Saúde mental. Economia solidária. Reabilitação psicossocial.

\section{MENTAL HEALTH AND SOCIAL ECONOMY: ESTRATEGIES OF PSICOSSOCIAL REHABILITATION}

\section{Abstract}

This paper have for objective to present considerations as for by one extension project developed on the year of 2006, in a partnership among the running of Psychology from

\footnotetext{
${ }^{1}$ O nome do projeto era Economia Solidária e Geração de Renda: capacitação e implantação de uma cooperativa de produtos artesanais no CAPS II de Criciúma, SC.
} 
UNESC and the Center of Attention Psicossocial (CAPS II). I tend presupposed the social economy, the project he sought , in conjunction with the users, he constructed an association of users bring up opportunity strategies of generation of income and rehabilitation psicossocial. Along a year of activity, as affiliation was constituting and today is coordinates bristles users.

Keywords: Mental Health. Social Economy. Rehabilitation Psicossocial.

\section{Introdução}

A reforma psiquiátrica, no Brasil, mostra-se uma importante mudança, sensata e eficiente, pois tal manifestação política e social apresenta-se como um projeto coletivo de substituição dos serviços oferecidos na área de saúde mental, substituindo o modelo hospitalocêntrico por uma rede composta por serviços como os Centros de Atenção Psicossocial (CAPS). Na opinião de Amarante (1995, p. 87), trata-se também de um processo “[...] de formulação crítica e prática, que tem como objetivos e estratégias o questionamento e elaboração de propostas de transformação do modelo clássico e do paradigma da psiquiatria”. Desta forma, mais do que uma mudança no modelo assistencial, a reforma psiquiátrica significa uma mudança ética no olhar sobre a loucura, na medida em que insere em ambientes institucionais uma compreensão sobre o adoecimento psíquico para além de um olhar biologicista.

Do início de 2003 até 2005, 5.400 leitos em hospitais psiquiátricos foram reduzidos. Não obstante, mesmo com esses avanços da reforma psiquiátrica, novos percalços se colocam no caminho da reintegração social dos usuários do serviço substitutivo (BRASIL, MINISTÉRIO DA SAÚDE, 2005a).

Apenas assistências como o Programa de Volta Para a Casa não são suficientes. ${ }^{2}$ É preciso estabelecer parcerias que abranjam não somente a esfera dos órgãos públicos vinculados à área da saúde, mas também outras práticas sob a inspiração da economia solidária, de forma que a reabilitação psicossocial esteja atrelada a propostas de criação de oportunidades de geração de renda e inclusão social. Isto é, toda conjuntura de políticas

\footnotetext{
${ }^{2}$ O programa De Volta Para a Casa foi criado pelo Ministério da Saúde em 2003 para reintegrar socialmente pessoas que sofrem de transtornos mentais egressas de longas internações em hospitais psiquiátricos. Essas pessoas, ao retornarem às suas residências, recebem um auxílio financeiro no valor de $\mathrm{R} \$ 250,00$ do Governo para custear suas despesas pessoais e com medicamentos.
} 
públicas precisa necessariamente levar em conta aspectos que envolvam a recuperação e a promoção à saúde nos aspectos subjetivos.

Subjetividade, saúde e trabalho, necessariamente dizem respeito a modos de experiências vivenciados pelos sujeitos. Assim, essas questões envolvem uma complexidade que, na opinião de Civiatta (2004a), estão ligadas a processos de natureza ontológica e histórica, na medida em que o homem é constituído e se constitui de maneiras diferenciadas conforme as épocas. No que diz respeito ao trabalho observamos que

[...] os sentidos atribuídos ao trabalho mudam se analisarmos a relação do cidadão e do escravo com o trabalho na Grécia, do senhor de engenho com o escravo no Brasil Colonial, do operário e do patrão no modelo industrial fordista, do jovem trabalhador autônomo da nova economia no século XXI e daqueles que inserem nos projetos de economia solidária (ES) (NARDI; BALEM; FERNANDES, et al. 2006, p. 320).

Quando falamos em outras propostas de intervenção na área de saúde mental como alternativas de geração de renda, necessariamente falamos de um outro olhar em torno do próprio ser humano, nesse caso, não reduzido a questões de cunho biológico ou econômico, mas sim, relacionado a aspectos complexos que envolvem questões de gênero, raça, ou classe social que, na opinião de Fischer (2004b), formam uma conjuntura cujo desenvolvimento de práticas libertadoras favorece o enfrentamento da exclusão social e de reabilitação psicossocial. Tal interlocução entre os elementos, saúde, subjetividade e trabalho acabam permitindo que oficinas de geração de renda, associações e cooperativas no CAPS acabem contribuindo para o bem-estar, a autoestima e uma efetiva inclusão social dos usuários. A economia solidária vem se consolidando como uma parceira importante neste processo, pois ela

[..] retorna com redobrado vigor em nosso país, nos anos 90, como reposta ao desemprego em massa e à exclusão social, resultantes de sucessivas crises financeiras combinadas com a abertura desmesurada do mercado interno a importações e com a adoção intensa de inovações poupadoras de mão-de-obra. (SINGER, 2001, p. 53)

Baseados em Singer (2002), podemos afirmar que a economia solidária é uma alternativa ao modo de produção capitalista, na medida em que seus princípios são a coletividade e a cooperação, ao passo que, no modelo capitalista, o que impera são valores como o individualismo e a competição.

Segundo Delgado (2005b), as múltiplas experiências brasileiras de geração de renda e de cooperativas ou associações articuladas com a rede de atenção psicossocial mostram-se 
cada vez mais eficientes na inclusão social pelo trabalho. Isso porque a economia solidária e a reforma psiquiátrica têm como foco o mesmo objetivo: a luta contra a exclusão social. Ainda de acordo com Delgado (2005c, p. 17)

[...] a questão das oficinas de geração de renda, a inclusão social pelo trabalho, as cooperativas, são instrumentos extremamente eficazes. Se pensarmos uma experiência internacional como a italiana, veremos que o trabalho das cooperativas sociais e das empresas sociais foram experiências cruciais para que, nas regiões da Itália, onde a reforma italiana deu certo, tais iniciativas pudessem se consolidar, aos olhos da opinião pública, como experiências positivas e muito bem sucedidas. Um componente fundamental da experiência italiana, que é importante na influencia que ela tem sobre nós do Brasil, é justamente da inclusão social pelo trabalho das empresas sociais e das cooperativas. Em vários países do mundo, essa questão do trabalho protegido e da inclusão pelo trabalho é um componente fundamental do processo de mudança do modelo de assistência.

Assim, um projeto de extensão, que procure trabalhar com esta perspectiva, deve procurar não somente instrumentalizar os sujeitos, mas incorporar também a inclusão social pelo trabalho do usuário do serviço de saúde mental através de um diálogo interdisciplinar, englobando os fatores psicossociais dos indivíduos.

O presente artigo aqui apresentado é resultado de uma ação que aconteceu efetivamente no Centro de Atenção Psicossocial (CAPS II), durante o ano de 2006, em parceria com o curso de Psicologia da UNESC desenvolvendo oficinas de geração de renda e cidadania com os usuários e familiares do CAPS II. Tal grupo teve por objetivo capacitar e instrumentalizar os usuários da entidade na estruturação de uma associação de trabalho pautada nos princípios da economia solidária. A seguir apresentaremos algumas considerações acerca de nossa prática, destacando, de início, a metodologia de trabalho utilizada, para em seguida apresentarmos uma análise em torno da constituição da associação de usuários e demais atividades do projeto. Por fim, destacaremos nossas considerações finais sobre o trabalho correlacionando a prática aos pressupostos da economia solidária e da reabilitação psicossocial.

\section{Material e Métodos}

O presente projeto de extensão desenvolveu sua metodologia de intervenção através das seguintes atividades:

a) oficina de cidadania: teve como foco os próprios usuários do CAPS. Foi composta por dinâmicas de grupo relacionadas a temas, como o acesso à cidadania, dinâmica exclusão - inclusão, exposição de filmes, e saídas de campo. Nesta oficina, os usuários 
confeccionaram uma cartilha sobre saúde mental, cidadania e inclusão no mercado de trabalho. A periodicidade da oficina foi semanal, com carga horária total de 72h.

b) oficina sobre identidade e autoestima: teve o objetivo de propiciar em conjunto com a população-alvo, reflexões sobre a subjetividade e a constituição do sujeito a partir de uma perspectiva materialista dialética. Sua metodologia foi composta por dinâmicas de grupo, vídeos-debate, seminários com a equipe técnica do projeto e funcionários do CAPS II. A periodicidade da oficina foi semanal, com carga horária total de 90h.

c) oficina de legislação trabalhista e cooperativismo: teve como objetivo, fomentar a reflexão sobre a legislação trabalhista por parte dos usuários e familiares. A metodologia de trabalho foi composta por atividades expositivas, vídeos-debate, seminários com consultor jurídico e palestras com profissionais da área de microcrédito. A carga horária total da atividade foi 54h.

d) oficina de customização de roupas: a atividade consistiu em aprimorar, nos usuários, as técnicas de criação de materiais de customização de roupas com o intuito de criar uma possível alternativa de geração de renda e economia solidária dos usuários do CAPS II. A atividade foi ministrada pela artesã e a terapeuta ocupacional do Centro de Atenção Psicossocial. A carga horária total da atividade foi de 90h.

e) saída de campo: esta atividade consistiu em uma saída de campo por parte do corpo técnico do projeto e de usuários do serviço à cidade de Porto Alegre, tendo como finalidade conhecer outros empreendimentos solidários desenvolvidos na área de saúde mental.

\section{Resultados e Análise}

Segundo o economista Paul Singer (2005d), a economia solidária e a reforma psiquiátrica possuem a mesma preocupação, que é a luta contra a exclusão social. Ou seja, ambas, se configuram enquanto estratégias de enfrentamento à exclusão provocada pelo sistema capitalista.

Nosso projeto teve como objetivo geral promover no Centro de Atenção Psicossocial II de Criciúma, a construção de uma associação de usuários a partir de uma perspectiva da 
economia solidária. Neste sentido, trabalhamos com um grupo composto por quarenta e oito pessoas de sexo masculino e feminino, compostos por usuários, familiares e técnicos do CAPS que foram capacitados e orientados na construção de uma associação de produção e comercialização de produtos artesanais como a compostagem de roupas.

O projeto foi composto por reuniões, oficinas, assembléias, seminários, minicursos e vídeos-debates. Foram abordados aspectos teóricos referentes à cidadania, autoestima, identidade, cooperativismo e legislação trabalhista. Além disso, foi confeccionado um caderno de saúde mental, trabalho e cidadania pelos próprios usuários. Essas atividades ocorreram tendo como pressupostos a perspectiva do trabalho com grupos populares. De acordo com Pereira (1982), a efetivação de práticas com grupos populares possibilita uma busca plena de autonomia e libertação.

Os usuários participaram de oficinas práticas visando à confecção de produtos artesanais e de compostagem de roupas. As peças foram desenvolvidas em parceria com a Terapeuta Ocupacional e tratava-se de pintura de camisetas, seção de corte e costura e, ainda, o aproveitamento de sobras de tecidos na confecção de peças ornamentais conhecidas como "fuxicos" 3 .

Soma-se a isso, uma viagem de intercâmbio entre os participantes do projeto, usuários do CAPS e profissionais da instituição a uma cooperativa existente no município de Porto Alegre. A intenção de tal viagem foi possibilitar que alguns usuários do serviço tivessem a oportunidade de conhecer outro empreendimento solidário para que, assim, houvesse a troca de informações e experiências sobre alternativas já existentes.

Como resultados efetivos além da própria constituição da associação de usuários com base em um perfil democrático e econômico-solidário com diretoria e associados regidos por estatuto votado em assembléia geral, o projeto também contou com a distribuição das cartilhas sobre saúde mental, trabalho e cidadania em escolas, empresas e outros espaços do município de Criciúma. Soma-se a isso o fato da associação de usuários do CAPS II ter conseguido um espaço permanente na feira de artesanatos e artesões promovida semanalmente pela Secretaria Municipal de Desenvolvimento Social da Prefeitura de Criciúma.

\footnotetext{
${ }^{3}$ O Nome "fuxico" tem uma origem um tanto curiosa. Surgiu no Nordeste, quando as mulheres se reuniam para desenvolver a arte da costura e aproveitavam para "falar da vida alheia". Hoje é um ornamento muito utilizado até por marcas famosas do ramo da moda. Por ser composto por sobras de tecidos, e, portanto, ter baixo custo financeiro, o "fuxico" se apresenta como alternativa viável dentro de uma proposta de geração de renda, possibilitando que, com poucos recursos, estilize-se roupas e acessórios contribuindo para uma valorização estética.
} 


\title{
Considerações Finais
}

Paul Singer (2002), diz que de modo algum o capitalismo e os seus respectivos modos de produção são algo natural. Isto significa dizer que o capitalismo é fruto de uma construção histórica do homem para o homem e que hoje se apresenta enquanto uma ideologia que prioriza princípios como a competição, o individualismo, e o maior acúmulo possível de capital.

A economia solidária vem cada vez mais se consolidando enquanto uma possível estratégia de resistência ao capitalismo. Seja dentro das universidades, onde é discutida por professores e acadêmicos, seja na comunidade aonde trabalhadores reunidos em conjunto decidem comercializar produtos desenvolvidos de maneira coletiva, ou ainda em instituições públicas nas quais há uma parceria entre a população beneficiada pelo serviço e o corpo profissional da instituição.

Para Mance (2002, p. 19),

\begin{abstract}
A construção de um mundo novo, onde cada uma pode colaborar com o bem-viver de todos, através de práticas sociais e econômicas solidárias, representa a afirmação da liberdade humana. Nas muitas práticas solidárias existentes percebemos ricas dimensões educativas. Quando consumimos produtos e serviços das redes de colaboração solidária contribuímos para manter postos de trabalho e proteger o meio ambiente. No entanto, mais do que simples transações econômicas, aprendemos e ensinamos, uns com os outros, o valor do trabalho como fonte geradora de toda riqueza material e cultural da sociedade.
\end{abstract}

Ao final de um ano de atividade, os participantes do projeto consolidaram dentro de um ambiente institucional uma possibilidade de inserção no mercado de trabalho e de geração de renda por intermédio de uma associação constituída sob o viés do associativismo solidário.

Sendo assim, pode-se afirmar que o projeto contribuiu para uma efetiva reabilitação psicossocial dos usuários daquele serviço substitutivo. Haja vista que "O processo de reabilitação psicossocial seria, então, um processo de reconstrução, um exercício pleno de cidadania, e, também, de plena contratualidade nos três grandes cenários: habitat, rede social e trabalho com valor social” (SARACENO, 2001).

As práticas desenvolvidas possibilitaram a efetivação de um projeto político cuja dimensão se estabeleceu no exercício da promoção da saúde mental e da autonomia.

Portanto, tal projeto cumpriu seu papel, que foi o de inserir, junto aos usuários, toda uma discussão em torno de propostas efetivas de cidadania e de inclusão social. 


\section{Referências}

AMARANTE, Paulo. Loucos pela Vida: a trajetória da reforma psiquiátrica no Brasil. Rio de Janeiro: Fiocruz, 1995.

BRASIL, MINISTÉRIO DA SAÚDE. SECRETARIA DE ATENÇÃO À SAÚDE. DEPARTAMENTO DE AÇÕES PROGRAMÁTICAS ESTRATÉGICAS. Saúde Mental e Economia Solidária: inclusão social pelo trabalho. Brasília: Editora do Ministério da Saúde, 2005a.

CIVIATTA, Maria. A Memória do Trabalho e dos Trabalhadores: a fotografia como fonte histórica. Revista de Ciências Sociais da UINISINOS. São Leopoldo, v. 40, n. ${ }^{0}$ 164, p. 17 54, $2^{\circ}$ sem, 2004.

DELGADO, Pedro Gabriel. Reforma Psiquiátrica e Inclusão Social pelo Trabalho. (In) BRASIL, MINISTÉRIO DA SAÚDE. SECRETARIA DE ATENÇÃO À SAÚDE. DEPARTAMENTO DE AÇÕES PROGRAMÁTICAS ESTRATÉGICAS. Saúde Mental e Economia Solidária: inclusão social pelo trabalho. Brasília: Editora do Ministério da Saúde, 2005b.

Economia Solidária e Saúde mental. (In) BRASIL, MINISTÉRIO DA SAÚDE. SECRETARIA DE ATENÇÃO À SAÚDE. DEPARTAMENTO DE AÇÕES PROGRAMÁTICAS ESTRATÉGICAS. Saúde Mental e Economia Solidária: inclusão social pelo trabalho. Brasília: Editora do Ministério da Saúde, 2005c.

FISCHER, Maria Claro Bueno. Notas Sobre Saberes da Experiência e a Constituição de Empreendimentos Econômicos e Solidários. Revista de Ciências Sociais da UINISINOS. São Leopoldo, v. 40, n. ${ }^{\circ}$ 164, p. 139 - 152, 2º sem, 2004.

MANCE, Euclides André (Org.) Como Organizar Grupos Populares. Rio de Janeiro: DP \& A, 2002.

NARDI, Henrique Caetano. BALEM, Denise. FERNANDES, Janice Mendes et al. Subjetividade e Solidariedade: a diversidade das formas de implicação dos jovens na economia solidária. Revista Psicologia. Reflexão e Critica. Vol.19, nº 2, p.320-328, 2006.

PEREIRA, Willian César Castilho. Dinâmica de Grupos Populares. Petrópolis: Vozes, 1982.

SARACENO, Benedetto. Reabilitação Psicossocial: uma estratégia para o milênio. (In) PITTA, Ana. Reabilitação Psicossocial no Brasil. São Paulo: HUCITEC, 2001. 
SINGER, Paul. Saúde Mental e Economia Solidária. (In) BRASIL, MINISTÉRIO DA SAÚDE. SECRETARIA DE ATENÇÃO À SAÚDE. DEPARTAMENTO DE AÇÕES PROGRAMÁTICAS ESTRATÉGICAS. Saúde Mental e Economia Solidária: inclusão social pelo trabalho. Brasília: Editora do Ministério da Saúde, 2005d.

.Introdução à Economia Solidária. São Paulo: Fundação Perseu Abramo, 2002.

A Economia Solidária Como Resposta e Estratégia. (In) BENTO, Maria Aparecida Silva; CASTELAR, Marilda. Inclusão no Trabalho: desafios e perspectivas. São Paulo: Casa do Psicólogo, 2001. 